\title{
Syntheses, characterization and crystal structures of potassium and barium complexes of a Schiff base ligand with different anions
}

\author{
BHAVESH PARMAR ${ }^{\mathrm{a}}$, KAMAL KUMAR BISHT $^{\mathrm{a}, \mathrm{b}}$, PRATYUSH MAITI $^{\mathrm{c}}$, PARIMAL PAUL $^{\mathrm{a}, \mathrm{b}}$, \\ and ERINGATHODI SURESH ${ }^{\mathrm{a}, \mathrm{b}, *}$ \\ ${ }^{a}$ Analytical Discipline and Centralized Instrument Facility, ${ }^{\mathrm{b}}$ Academy of Scientific and Innovative Research \\ (AcSIR), ${ }^{\mathrm{c} S c a l e-u p}$ and Process Engineering Unit, CSIR-Central Salt and Marine Chemicals Research \\ Institute, Council of Scientific and Industrial Research, G B Marg, Bhavnagar 364 002, Gujarat, India \\ e-mail: esuresh@csmcri.org; sureshe123@rediffmail.com
}

MS received 5 April 2014; accepted 1 September 2014

\begin{abstract}
New pseudopolymorph of a O,N,N'-donor hydrazone ligand, 2-pyridylcarboxaldehyde isonicotinoylhydrazone $(\mathbf{L})$ and its discrete complexes with $\mathrm{K}^{+}$and $\mathrm{Ba}^{2+}$ have been reported. $\mathbf{L}$ forms isostructural dinuclear complexes with $\mathrm{K}^{+}$when bromide and iodide were employed as counter anions. However, a monomeric complex in the case of $\mathrm{Ba}^{2+}$ with existence of coordinated as well as lattice perchlorate counter anions was observed. All compounds were characterized by single crystal X-ray analysis and other physicochemical techniques. Structural analysis and spectral features of all compounds are described in detail.
\end{abstract}

Keywords. Potassium; Barium; Schiff base; dinuclear complex; 2-pyridylcarboxaldehyde isonicotinoylhydrazone; single crystal x-ray analysis.

\section{Introduction}

Crystal engineering utilizes intermolecular interactions and offers the synthesis of molecular solids from neutral or ionic building blocks. ${ }^{1}$ Supramolecular assemblies involving $\mathrm{O}, \mathrm{N}, \mathrm{N}$ '-donor organic molecules and coordination compounds thereof have been of much research interest owing to their potent biological activity as well as variety of structural diversity. ${ }^{2}$ Significant structural differences observed in various complexes involving $\mathrm{O}, \mathrm{N}, \mathrm{N}$ '-donor molecules have shown to impart diverse features such as catalytic property and second harmonic generation. ${ }^{3}$

$\mathrm{O}, \mathrm{N}, \mathrm{N}$ '-donor hydrazone ligands which are often synthesized by Schiff base condensation have been excellent supramolecular precursors for their ability to exist in keto- and enol- tautomeric forms (scheme 1). Interestingly, hydrazone ligands can coordinate with metal centres either as neutral molecule or deprotonated anionic form, which enhances the coordination diversity in the resulting architectures (scheme 1). A large number of mono- and dinuclear metal complexes are available in literature involving hydrazone ligands and transition metal ions. In fact, the Schiff base, 2-pyridylcarboxaldehyde isonicotinoylhydrazone $(\mathbf{L})$, has been exploited to realize a range of organic

*For correspondence co-crystals/salts and coordination compounds with different transition metal ions. ${ }^{4,5}$ An oxidized derivative of L (N-(isonicotinoyl)-N'-(picolinoyl)hydrazine), which has been obtained in presence $\mathrm{Fe}$ (III) ions has also been reported. ${ }^{5}$ Moreover, Bernhardt et al. have explored the notable iron chelator efficacy of numerous transition metal complexes of $\mathbf{L}$ and derivative ligands. ${ }^{6}$

Recently, $\mathbf{L}$ has been utilized to fabricate extended materials such as coordination polymers or metal organic frameworks. ${ }^{7}$ Dehnen et al. reported mixed ligand In(III) helical coordination polymers in its neutral as well as anionic forms involving aryl thiolates and $\mathbf{L}$. Interestingly, the coordination polymer possessing anionic form showed a centrosymmetric structure, whereas, the one comprising neutral hydrazone revealed non-centrosymmetric structure exhibiting second harmonic generation (SHG) effect. $^{8}$

On the contrary, variation in the solid state forms of biologically active substances remains of significant interest. ${ }^{9}$ Different solid state forms of any molecule of interest; typically, an active pharmaceutical ingredient may exhibit different stability, dissolution or solubility behaviour. Thus, the studies on the polymorphic and pseudopolymorphic forms of potent organic molecules remain the subject of interest among crystal engineers. ${ }^{9}$ We have been involved in the studies on crystal engineering aspects and supramolecular interactions of self assembled systems including hybrid 


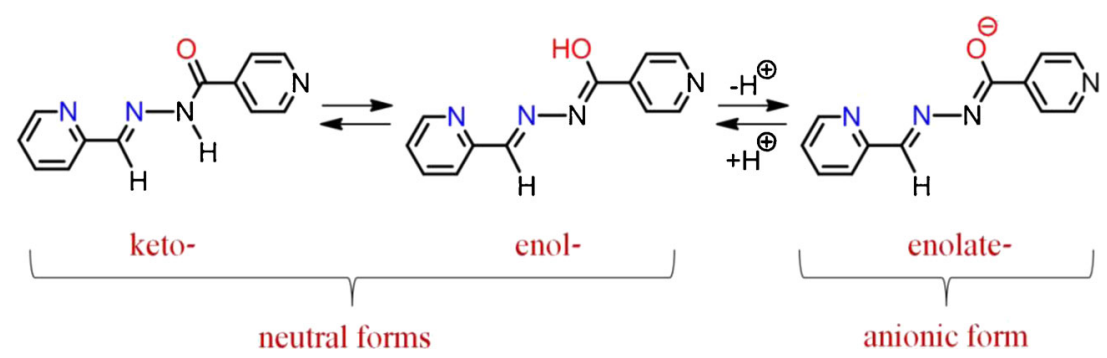

Scheme 1. Neutral keto-enol tautomers and anionic enolate form of O,N,N'-donor, $\mathbf{L}$.

organic materials, discrete metal complexes and coordination polymers. ${ }^{10}$ Despite the rich literature reports on the coordination compounds of $\mathbf{L}$ with transition metals, coordination behaviour of $\mathbf{L}$ towards the alkali and alkaline earth metal ions are scantly investigated. The present study is outlined to understand the crystal engineering aspects of Schiff base ligand $\mathbf{L}$ and its coordination behaviour towards the alkali and alkaline metal ions $\mathrm{K}^{+}$and $\mathrm{Ba}^{+2}$. Thus, a new polymorphic form of ligand $\mathbf{L}$ has been crystallized and complexes $\mathbf{1 , 2}$ and $\mathbf{3}$ have been synthesised by treatment of the metal precursors with $\mathbf{L}$ in appropriate stoichiometry. $\mathbf{L}$ and all three complexes have been characterized by single crystal X-ray diffraction analysis and other physicochemical techniques.

\section{Experimental}

\subsection{Materials and methods}

All reagents and solvents were purchased from commercial sources and were used without further purification. Distilled water was used for synthetic manipulations. CHNS analyses were done using a Perkin-Elmer $2400 \mathrm{CHNS} / \mathrm{O}$ analyzer. ${ }^{1} \mathrm{H}$ and ${ }^{13} \mathrm{C}$ NMR spectra for the ligands and complexes were recorded on Bruker $\mathrm{AX}$ 500 spectrometer $\left(500 \mathrm{MHz}\right.$ at temperature $25^{\circ} \mathrm{C}$ and was calibrated with respect to internal reference TMS). IR spectra were recorded using $\mathrm{KBr}$ pellets on a PerkinElmer GX FTIR spectrometer. For each IR spectra 10 scans were recorded at $4 \mathrm{~cm}^{-1}$ resolution. TGA was carried out using Mettler Toledo Star SW 8.10. Absorption spectra were recorded using Shimadzu UV-3101PC spectrometer. X-ray powder diffraction data were collected using a Philips X-Pert MPD system with $\mathrm{CuK} \alpha$ radiation. Single crystal structures were determined using BRUKER SMART APEX (CCD) diffractometer.

\subsection{Synthesis of 2-pyridylcarboxaldehyde isonicotinoylhydrazone $(\boldsymbol{L})$}

2-pyridylcarboxaldehyde isonicotinoylhydrazone or (E)-N'-(pyridin-2-ylmethylene) isonicotinohydrazide
(L) was synthesized by adopting a reported procedure with slight modifications. ${ }^{11}$ Pyridine-2-carboxaldehyde $(1.0 \mathrm{~mL}, 10 \mathrm{mmol})$ and isonicotinohydrazide $(1.37 \mathrm{gm}$, $10 \mathrm{mmol}$ ) were dissolved in $25 \mathrm{~mL}$ of ethanol and few drops of acetic acid were added. Resulted solution was refluxed with continuous stirring for $8 \mathrm{~h}$ and then the solvent was reduced by rotator evaporation to $10 \mathrm{~mL}$ which on cooling to room temperature yielded white precipitate. The precipitate thus obtained was washed with cold methanol and recrystallized in ethanol. Yield $=85 \% .{ }^{1} \mathrm{H}$ NMR $\left(\right.$ DMSO- $\left._{d 6}\right): \delta 7.46(\mathrm{~m}, 1 \mathrm{H})$, $7.93(\mathrm{~m}, 4 \mathrm{H}), 8.50(\mathrm{~d}, 1 \mathrm{H}), 8.65(\mathrm{~d}, 1 \mathrm{H}), 8.81(\mathrm{~d}, 2 \mathrm{H})$, 12.26(s,1H). Elemental analysis $(\%)$ calc.: $\mathrm{C}, 63.71 ; \mathrm{H}$, 4.46; N, 24.76; found: C, 63.32; H, 4.72; N, 24.14; IR $\mathrm{cm}^{-1}(\mathrm{KBr})$ : 3446 (br), $3174(\mathrm{w}), 2998(\mathrm{~m}), 2365(\mathrm{w})$, 1665 (s), 1549 (s), 1472 (m), 1407 (w), 1346 (w), 1286 (s), $1148(\mathrm{~m}), 1073(\mathrm{~m}), 997(\mathrm{w}), 956(\mathrm{w}), 849(\mathrm{w})$, $787(\mathrm{w}), 749(\mathrm{w}), 688(\mathrm{~m}), 628(\mathrm{w}), 512(\mathrm{w})$.

\subsection{Crystallization of 2-pyridylcarboxaldehyde

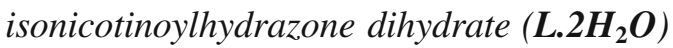

L (23 mg, $0.10 \mathrm{mmol})$ and $\mathrm{KNO}_{3}(11 \mathrm{mg}, 0.10 \mathrm{mmol})$ were dispersed in $7 \mathrm{~mL}$ of water-methanol solvent mixture (water : methanol $=1: 2.5$ ) and heated for $6 \mathrm{~h}$ at $75-80^{\circ} \mathrm{C}$ then cooled down to ambient temperature and allowed to evaporate slowly. X-ray quality fibrous needle shaped crystals were harvested in $\mathrm{ca} 2$ months time. Yield $=70.5 \%$. Elemental analysis (\%) calc.: C, 54.96; H, 5.38; N, 21.36; found: C, 54.77; H, 5.78; N, 20.87; IR cm ${ }^{-1}$ (KBr): 3450 (s), 3069 (m), 2928 (w), 2850 (w), 2362 (m), 1665 (s), 1567 (s), 1471 (w), 1437 (m), 1415 (m), 1363 (m), $1291(\mathrm{~s}), 1146(\mathrm{w}), 1067(\mathrm{~m}), 1001(\mathrm{w})$, $949(\mathrm{w}), 855(\mathrm{w}), 784(\mathrm{w}), 748(\mathrm{w}), 689(\mathrm{~s}), 522(\mathrm{w})$, $460(\mathrm{w})$.

\subsection{Synthesis of $\left[\mathrm{K}_{2} \mathrm{~L}_{4}\left(\mathrm{H}_{2} \mathrm{O}\right)_{2}\right] \mathrm{Br}_{2} \cdot 6 \mathrm{H}_{2} \mathrm{O}(\mathrm{1})$}

L $(23 \mathrm{mg}, 0.10 \mathrm{mmol})$ and $\mathrm{KBr}(12 \mathrm{mg}, 0.10 \mathrm{mmol})$ were dispersed in a mixture of $2 \mathrm{~mL} \mathrm{H}_{2} \mathrm{O}$ and $5 \mathrm{~mL}$ methanol and then refluxed for $6 \mathrm{~h}$. The reaction mixture was cooled to room temperature, filtered and 
allowed to evaporate slowly when fibrous needle shape crystals suitable for single crystal analysis were obtained after $40-45$ days. Yield $=74.2 \%$. Elemental analysis (\%) calc.: C, 44.79; H, 4.39; N, 17.41; found: C, 43.96; H, 5.01; N, 16.82; IR cm ${ }^{-1}$ (KBr): 3456 (br), $3163(\mathrm{w}), 3056(\mathrm{w}), 3008$ (m), 2925 (w), 2849 (w), 2360 (w), 2208 (w), 1664 (s), 1560 (s), 1480 (w), 1437 (w), 1409 (w), 1361 (m), 1300 (s), 1154 (m), 1065 (m), $948(\mathrm{w}), 850(\mathrm{w}), 775(\mathrm{w}), 686(\mathrm{~m}), 520(\mathrm{w})$.

\subsection{Synthesis of $\left[\mathrm{K}_{2} \mathrm{~L}_{4}\left(\mathrm{H}_{2} \mathrm{O}\right)_{2}\right] \mathrm{I}_{2} \cdot 6 \mathrm{H}_{2} \mathrm{O}$ (2)}

Method was same as adopted for $\mathbf{1}$ except KI (17 mg, $0.10 \mathrm{mmol}$ ) was used instead of $\mathrm{KBr}$. Yield $=78.4 \%$. Elemental analysis (\%) calc.: C, 41.74; H, 4.09; N, 16.23; found: C, 40.92; H, 4.24; N, 15.62; IR $\mathrm{cm}^{-1}$ (KBr): 3476 (br), 3173 (s), 3035 (m), 2866 (w), 2367 (w), $2215(\mathrm{w}), 1678$ (s),1547 (s), 1471 (w), 1430 (w), 1409 (w), 1361 (w), 1292 (s), 1147 (m), 1065 (m), 999 $(\mathrm{w}), 847(\mathrm{w}), 776(\mathrm{w}), 692(\mathrm{~m}), 480(\mathrm{w})$.

\section{$2.6\left\{\left[\mathrm{Ba}(\mathrm{L})_{2}(\mathrm{H} 2 \mathrm{O})_{2}\left(\mathrm{ClO}_{4}\right)\right] .\left(\mathrm{ClO}_{4}\right)\right\}(3)$}

$\mathrm{Ba}\left(\mathrm{ClO}_{4}\right)_{2}(168 \mathrm{mg}, 0.5 \mathrm{mmol})$ was dissolved in $5 \mathrm{~mL}$ $\mathrm{H}_{2} \mathrm{O}$ then $5 \mathrm{~mL}$ methanol was layered carefully over which $\mathbf{L}$ (112 mg, $0.5 \mathrm{mmol})$ dissolved in ethanol were layered. The container was covered and kept for slow diffusion of reactants at room temperature which afforded white crystals within 45-50 days. Yield = $71.2 \%$. Elemental analysis (\%) calc.: C, 34.95; H, 2.93; N, 13.59; found: C, 35.11; H, 2.878; N, 14.17; IR cm ${ }^{-1}$ (KBr): 3546 (m), 3265 (s), 2932 (w), 2857 (w), 2364 (w), 1665 (s), 1552 (s), 1477 (w), 1438 (w), 1369 (w), 1293 (s), 1089 (s), 928 (w), 849 (w), $781(\mathrm{w}), 750(\mathrm{w})$, $694(\mathrm{w}), 627(\mathrm{~m}), 514(\mathrm{w})$.

\section{$2.7 \quad X$-ray crystallography}

Summary of crystallographic data and details of data collection for $\mathbf{L}$ and $\mathbf{1 - 3}$ is given in table 1. Single crystals with suitable dimensions were chosen under an optical microscope after immersing in paratone oil and mounted on a glass fibre for data collection. Intensity data for all the crystals were collected using $\mathrm{MoK}_{\alpha}$ $(\lambda=0.71073 \AA)$ radiation on a Bruker SMART APEX diffractometer equipped with CCD area detector at 150 $\mathrm{K}$ except for complex $\mathbf{3}$ for which data was collected at room temperature $(296 \mathrm{~K})$. The data integration and reduction were processed with SAINT software. ${ }^{12}$ An empirical absorption correction was applied to the collected reflections with SADABS. ${ }^{13}$ Structures were solved by direct methods using SHELXTL and were refined on $\mathrm{F}^{2}$ by the full-matrix least-squares technique using the program SHELXL-97. ${ }^{14,15}$ Hydrogen atoms attached to the organic ligand is either located from the difference Fourier map or fixed stereochemically in all the compounds. Hydrogen atoms of the coordinated/lattice water molecules are located from the difference Fourier map and kept fixed using DFIX card. In the case of Ba complex 3 some oxygen atoms of both perchlorate anions showed extensive disorder. The site and occupancy factor for the disordered oxygen atoms were determined using PART and FVAR cards of SHELXL-97 package. All non-hydrogen atoms were refined anisotropically till convergence is reached.

\section{Results and Discussion}

Conformational flexibility of ligand $\mathbf{L}$ makes it interesting and suitable for the crystal engineering studies. In fact, the O,N,N'-donor sites can presume syn and anti conformation as depicted in scheme 2. Structure of $\mathbf{L}$ reported by Richardson et al. revealed anti conformation by the pyridyl nitrogen with respect to the imine nitrogen. ${ }^{4}$ Interestingly, syn conformation is espoused by the ligand moiety in pseudopolymorph $\mathbf{L} .2 \mathbf{H}_{2} \mathrm{O}$ with water of crystallization which is reported in present work. This is attributable to the supramolecular interactions of $\mathbf{L}$ with lattice water molecules in the pseudopolymorph. It is worthy to mention that Cambridge Structure Database (CSD version 5.35) search involving $\mathbf{L}$ and transition metal ions showed 6 complexes involving keto tautomer and 12 complexes involving enol or enolate tautomers of $\mathbf{L} .^{7,8}$ However, no structural report on the $\mathrm{K}^{+}$and $\mathrm{Ba}^{+2}$ complexes of $\mathbf{L}$ is available in CSD and literature. Evidently, the current study presents first report on the complexation between $\mathbf{L}$ and alkali and alkaline earth metal ions. Complexes 1, 2 and $\mathbf{3}$ reveal the syn conformation of ligand moiety in keto tautomeric form which is attributable to the wrapping of ligand around the cations to facilitate effective tridentate chelation. Keto tautomeric form of $\mathbf{L}$ in all complexes as well as in its free states was established by ${ }^{1} \mathrm{H}$ and ${ }^{13} \mathrm{C}$ NMR spectra (figure S4). Structural features of ligand as well as all complexes are discussed in following sections.

\subsection{Crystal and molecular structure of $\mathbf{L} .2 \mathrm{H}_{2} \mathrm{O}$}

Ligand $\mathbf{L}$ was appropriately prepared by Schiff base condensation between pyridine-2-carboxaldehyde and isonicotinohydrazide. Crystal structure of the unhydrated form of ligand $\mathbf{L}$ was previously reported by Richardson et al. in Fdd2 space group of orthorhombic 
Table 1. Crystal data and refinement parameters for $\mathbf{L}$ and $\mathbf{1}-\mathbf{3}^{[\mathrm{a}]}$.

\begin{tabular}{|c|c|c|c|c|}
\hline Identification code & L. $2 \mathrm{H}_{2} \mathrm{O}$ & 1 & 2 & 3 \\
\hline Chemical formula & $\mathrm{C}_{12} \mathrm{H}_{14} \mathrm{~N}_{4} \mathrm{O}_{3}$ & $\mathrm{~K}_{2} \mathrm{C}_{48} \mathrm{H}_{56} \mathrm{Br}_{2} \mathrm{~N}_{16} \mathrm{O}_{12}$ & $\mathrm{~K}_{2} \mathrm{C}_{48} \mathrm{H}_{56} \mathrm{I}_{2} \mathrm{~N}_{16} \mathrm{O}_{12}$ & $\mathrm{BaC}_{24} \mathrm{H}_{24} \mathrm{Cl}_{2} \mathrm{~N}_{8} \mathrm{O}_{12}$ \\
\hline Formula weight & 262.27 & 1287.11 & 1381.09 & 824.75 \\
\hline Crystal Colour & Colourless & Pale-White & Yellow & White \\
\hline Crystal Size (mm) & $0.25 \times 0.05 \times 0.04$ & $0.11 \times 0.08 \times 0.05$ & $0.26 \times 0.08 \times 0.07$ & $0.60 \times 0.40 \times 0.30$ \\
\hline Temperature $(\mathrm{K})$ & $150(2)$ & $150(2)$ & $150(2)$ & $296(2)$ \\
\hline Crystal System & Monoclinic & Triclinic & Triclinic & Triclinic \\
\hline Space Group & $\mathrm{P} 2{ }_{1} / \mathrm{n}$ & P-1 & $\mathrm{P}-1$ & $\mathrm{P}-1$ \\
\hline $\mathrm{a}(\AA)$ & $7.077(4)$ & $10.1656(13)$ & $10.2966(9)$ & $9.8642(17)$ \\
\hline $\mathrm{b}(\AA)$ & $14.237(8)$ & $12.7671(16)$ & $12.7918(11)$ & $10.8398(19)$ \\
\hline$c(\AA)$ & $12.632(7)$ & $13.0956(17)$ & $13.2334(11)$ & $15.784(3)$ \\
\hline$\alpha\left(^{\circ}\right)$ & 90 & $111.469(2)$ & $110.6820(10)$ & $84.846(3)$ \\
\hline$\beta\left(^{\circ}\right)$ & $98.248(12)$ & $102.801(2)$ & $102.7650(10)$ & $74.006(2)$ \\
\hline$\gamma\left({ }^{\circ}\right)$ & 90 & $106.544(2)$ & $106.8600(10)$ & $87.718(3)$ \\
\hline $\mathrm{Z}$ & 4 & 1 & 1 & 2 \\
\hline $\mathrm{V}\left(\AA^{3}\right)$ & $1259.5(13)$ & $1411.5(3)$ & $1455.2(2)$ & $1615.6(5)$ \\
\hline Density $\left(\mathrm{Mg} / \mathrm{m}^{3}\right)$ & 1.383 & 1.514 & 1.576 & 1.695 \\
\hline$\mu\left(\mathrm{mm}^{-1}\right)$ & 0.102 & 1.657 & 1.295 & 1.466 \\
\hline $\mathrm{F}(000)$ & 552 & 660 & 696 & 820 \\
\hline Reflections Collected & 6176 & 11807 & 12117 & 13325 \\
\hline Independent Reflections & 2204 & 6031 & 6210 & 6916 \\
\hline $\mathrm{R}_{\text {int }}$ & 0.0852 & 0.0376 & 0.0196 & 0.0177 \\
\hline Number of parameters & 226 & 401 & 402 & 496 \\
\hline GOF on $\mathrm{F}^{2}$ & 1.122 & 1.111 & 1.156 & 1.035 \\
\hline FinalR $_{1} / \mathrm{wR}_{2}(\mathrm{I} \geq 2 \sigma(\mathrm{I})$ & $0.0792 / 0.1536$ & $0.0597 / 0.1163$ & $0.0349 / 0.0805$ & $0.0286 / 0.0787$ \\
\hline Weighted $\mathrm{R}_{1} / \mathrm{wR}_{2}$ (all data) & $0.1183 / 0.1700$ & $0.0780 / 0.1227$ & $0.0382 / 0.0821$ & $0.0301 / 0.0800$ \\
\hline CCDC number & 992911 & 992912 & 992913 & 992914 \\
\hline
\end{tabular}

${ }^{[\mathrm{a}]} \mathrm{R}=\Sigma\|\mathrm{Fo}|-| \mathrm{Fc}\| / \Sigma|\mathrm{Fo}| ; \mathrm{wR}=\left[\Sigma \mathrm{w}\left(\mathrm{Fo}^{2}-\mathrm{Fc}^{2}\right)^{2} / \Sigma \mathrm{w}\left(\mathrm{Fo}^{2}\right)^{2}\right]^{1 / 2}$

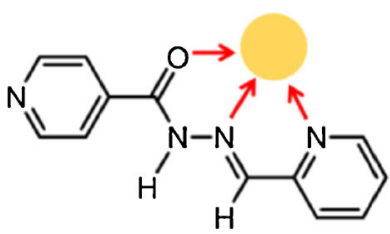

Syn-

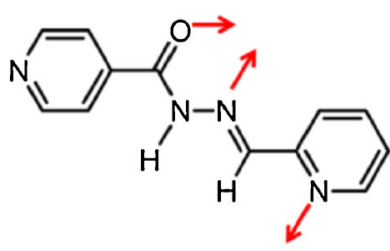

Anti-
Scheme 2. Syn- and anti-conformations of O,N,N'-donor L.

system. ${ }^{4}$ However, colourless shiny single crystals of new pseudopolymorph $\mathbf{L}$. $\mathbf{2} \mathbf{H}_{\mathbf{2}} \mathbf{O}$ suitable for X-ray crystallography were harvested from slow evaporation of methanol/water mixture in presence of potassium nitrate. Pseudopolymorph $\mathbf{L}$ crystallized along with two water molecules as solvent of crystallization in monoclinic system with $\mathrm{P} 2{ }_{1} / \mathrm{n}$ Space group (figure 1a). Crystal structure revealed that $\mathbf{L}$ moiety is almost planar with the syn conformation adopted by the pyridyl nitrogen $\mathrm{N} 1$ with respect to the imine nitrogen $\mathrm{N} 2$ which is the favourable conformation to make tridentate chelation in wrapping around the metal upon coordination. In an attempt to understand the supramolecular interactions we have analyzed the packing and hydrogen bonding interactions in detail. Packing diagram with hydrogen bonding interactions viewed down $a$ axis is depicted in figure 1c. Pairs of $\pi$ stacked $\mathbf{L}$ moieties in opposite orientations are engaged along $b$-axis with the centroid... centroid stacking distance between the pyridyl rings are $3.45 \AA$ and $3.56 \AA$ respectively. Lattice water molecules are positioned between the $\pi$ stacked $\mathbf{L}$ layers and involved in extensive hydrogen bonding interactions generating a two dimensional network.

Close up view of the various hydrogen bonding contacts are depicted in figure $1 \mathrm{~b}$. Thus, $\mathrm{O} 2$ and $\mathrm{O} 3$ are involved as a donor and making $\mathrm{O}-\mathrm{H} \cdots \mathrm{O}$ and $\mathrm{O}-\mathrm{H} \cdots \mathrm{N}$ interactions with water oxygen $\mathrm{O} 3$, pyridyl nitrogen $\mathrm{N} 4$ and amide oxygen $\mathrm{O} 1$ and pyridyl nitrogen $\mathrm{N} 1$ respectively. Lattice water molecules $\mathrm{O} 2$, is involved as acceptor in $\mathrm{C}-\mathrm{H}$. . O interaction with imine hydrogen $\mathrm{H} 6$, pyridyl hydrogen $\mathrm{H} 9$ and $\mathrm{N}-\mathrm{H}$. . O contact with amide hydrogen H1C. Nevertheless, O3 is 
a
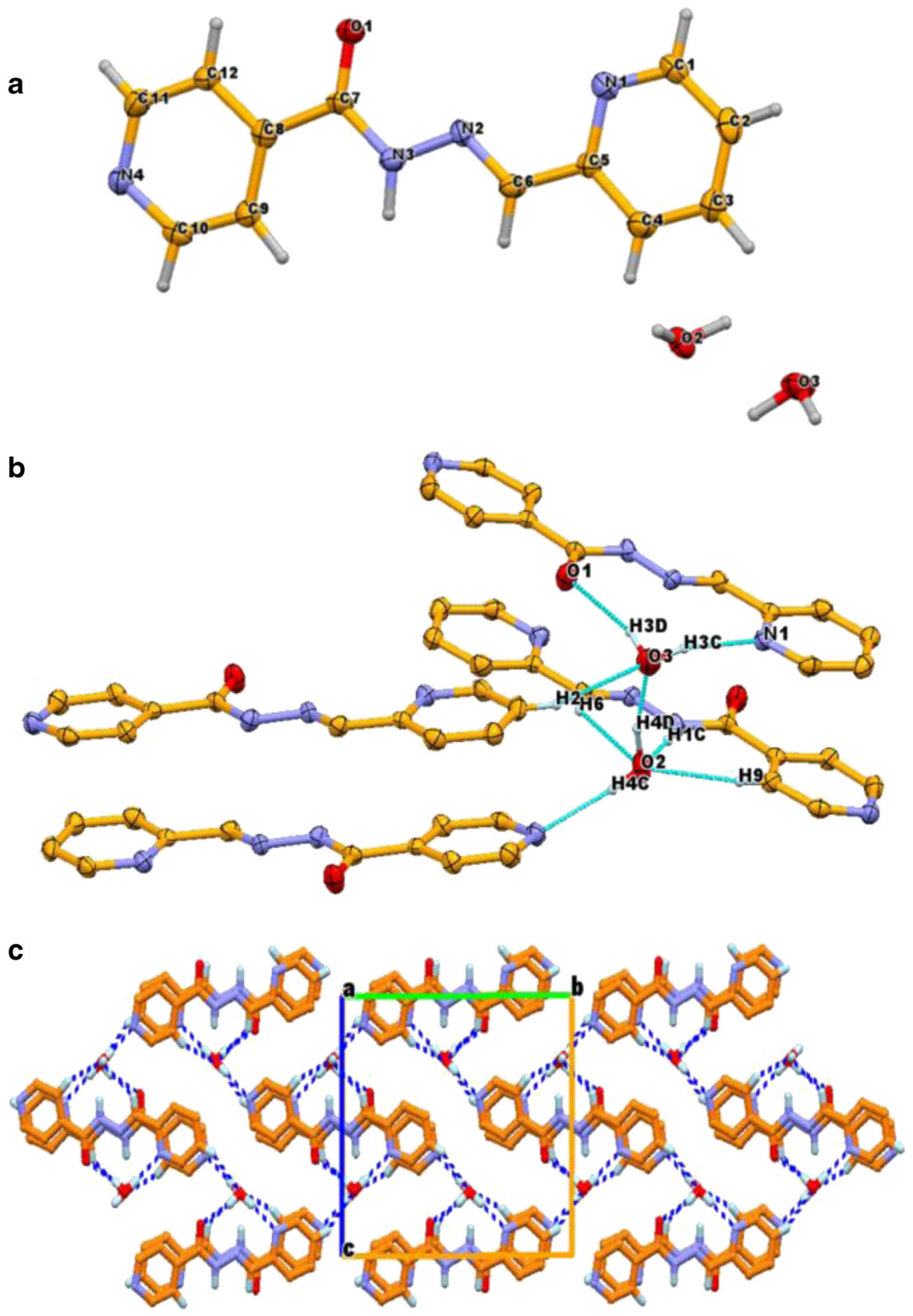

Figure 1. (a) ORTEP digam of $\mathbf{L} \cdot 2 \mathrm{H}_{2} \mathrm{O}$ with atom numbering scheme; (b) close-up view of various Hydrogen bonding interactions between the organic moiety and the lattice water molecules (turquoise dotted lines); (c) packing diagram viewed down a-axis showing the various supramolecular interactions in the two dimensional H-bonded network.

involved as acceptor in making $\mathrm{C}-\mathrm{H} \cdots \mathrm{O}$ interaction with the pyridyl hydrogen $\mathrm{H} 2$ and $\mathrm{O}-\mathrm{H} \cdots \mathrm{O}$ interaction with water hydrogen H4D respectively in making the two dimensional sheet like hydrogen bonded nets. Details of these H-bonding interactions with symmetry code are summarised in table 2.
3.2 Crystal and molecular structures of $\left[\mathrm{K}_{2} \mathrm{~L}_{4}\right.$ $\left.\left(\mathrm{H}_{2} \mathrm{O}\right)_{2}\right] \mathrm{Br}_{2} \cdot 6 \mathrm{H}_{2} \mathrm{O}(\mathrm{I})$ and $\left[\mathrm{K}_{2} \mathrm{~L}_{4}\left(\mathrm{H}_{2} \mathrm{O}\right)_{2}\right] \mathrm{I}_{2} \cdot 6 \mathrm{H}_{2} \mathrm{O}$ (2)

Compound $\mathbf{1}$ and $\mathbf{2}$ are isostructural dimers crystallized in triclinic system with P-1 space group and the structural description is limited to $\mathbf{1}$. Cationic part of the 
Table 2. Details of hydrogen bonding interactions observed in $\mathbf{L} .2 \mathrm{H}_{2} \mathrm{O}$ and 1-3.

\begin{tabular}{lccc}
\hline & \multicolumn{3}{c}{$\mathbf{L} .2 \mathrm{H}_{2} \mathrm{O}$} \\
$\mathbf{D}-\mathbf{H} \cdots \mathbf{A}$ & $\mathbf{d}(\mathbf{H} \cdots \mathbf{A})(\AA \mathbf{A})$ & $\mathbf{d}(\mathbf{D} \cdots \mathbf{A})(\mathbf{\AA})$ & $\angle \mathbf{D}-\mathbf{H} \cdots \mathbf{A}\left({ }^{\circ}\right)$ \\
$\mathrm{N}(3)-\mathrm{H}(1 \mathrm{C}) \cdots \mathrm{O}(2)^{1}$ & $1.94(4)$ & $2.848(5)$ & $172(4)$ \\
$\mathrm{O}(3)-\mathrm{H}(3 \mathrm{C}) \cdots \mathrm{N}(1)^{2}$ & $2.07(5)$ & $2.945(4)$ & $161(5)$ \\
$\mathrm{O}(3)-\mathrm{H}(3 \mathrm{D}) \cdots \mathrm{O}(1)^{2}$ & $2.10(6)$ & $2.939(4)$ & $164(5)$ \\
$\mathrm{O}(2)-\mathrm{H}(4 \mathrm{C}) \cdots \mathrm{N}(4)^{3}$ & $2.05(4)$ & $2.871(4)$ & $171(4)$ \\
$\mathrm{O}(2)-\mathrm{H}(4 \mathrm{D}) \cdots \mathrm{O}(3)^{4}$ & $1.75(4)$ & $2.785(4)$ & $165(4)$ \\
$\mathrm{C}(2)-\mathrm{H}(2) \cdots \mathrm{O}(3)^{5}$ & $2.57(3)$ & $3.416(5)$ & $155(3)$ \\
$\mathrm{C}(6)-\mathrm{H}(6) \cdots \mathrm{O}(2)^{1}$ & $2.58(3)$ & $3.345(5)$ & $138(2)$ \\
$\mathrm{C}(9)-\mathrm{H}(9) \cdots \mathrm{O}(2)^{1}$ & $2.37(3)$ & $3.255(4)$ & $158(3)$
\end{tabular}

Symmetry code: 1. 1/2-x,-1/2+y,1/2-z; 2. 1/2+x,3/2-y,1/2+z; 3. x,1+y,z; 4. -1+x,y,z; 5. 1-x,2-y,-z

$\begin{array}{lccc}\mathbf{D}-\mathbf{H} \cdots \mathbf{A} & \mathbf{d}(\mathbf{H} \cdots \mathbf{A})(\mathbf{A}) & \begin{array}{c}\text { Complex 1 } \\ \mathbf{d}(\mathbf{D} \cdots \mathbf{A})(\AA \mathbf{A})\end{array} & \left\langle\mathbf{D}-\mathbf{H} \cdots \mathbf{A}\left({ }^{\circ}\right)\right. \\ \mathrm{O}(3)-\mathrm{H}(3 \mathrm{~A}) \cdots \mathrm{N}(4)^{1} & 2.13(5) & 2.892(5) & 168(5) \\ \mathrm{O}(3)-\mathrm{H}(3 \mathrm{~B}) \cdots \mathrm{N}(5)^{2} & 2.16(6) & 2.862(5) & 168(7) \\ \mathrm{N}(3)-\mathrm{H}(3 \mathrm{~N}) \cdots \mathrm{Br}(1)^{3} & 2.65(4) & 3.414(3) & 168(4) \\ \mathrm{O}(4)-\mathrm{H}(4 \mathrm{~A}) \cdots \mathrm{O}(3)^{2} & 2.04(5) & 2.784(6) & 174(5) \\ \mathrm{O}(4)-\mathrm{H}(4 \mathrm{~B}) \cdots \mathrm{O}(6)^{2} & 2.02(5) & 2.748(5) & 156(5) \\ \mathrm{O}(5)-\mathrm{H}(5 \mathrm{~A}) \cdots \mathrm{N}(8)^{4} & 2.14(5) & 2.859(6) & 160(6) \\ \mathrm{O}(5)-\mathrm{H}(5 \mathrm{~B}) \cdots \mathrm{Br}(1)^{5} & 2.58(5) & 3.363(4) & 163(5) \\ \mathrm{O}(6)-\mathrm{H}(6 \mathrm{~A}) \cdots \mathrm{O}(5)^{3} & 1.93(7) & 2.707(6) & 174(5) \\ \mathrm{O}(6)-\mathrm{H}(6 \mathrm{~B}) \cdots \mathrm{Br}(1)^{6} & 2.61(5) & 3.372(4) & 171(4) \\ \mathrm{N}(7)-\mathrm{H}(7 \mathrm{~N}) \cdots \mathrm{O}(4)^{4} & 2.06(4) & 2.835(5) & 129.33 \\ \mathrm{C}(1)-\mathrm{H}(1) \cdots \mathrm{O}(2)^{2} & 2.4824 & 3.154(5) & 148.15 \\ \mathrm{C}(14)-\mathrm{H}(14) \cdots \mathrm{Br}(1)^{5} & 2.8987 & 3.721(4) & 136.44 \\ \mathrm{C}(18)-\mathrm{H}(18) \cdots \mathrm{O}(6)^{4} & 2.5405 & 3.414(5) & \end{array}$

Symmetry code: 1. 1-x,-y,1-z; 2. x, y, z; 3. 1-x,1-y,1-z; 4. -x,1-y,1-z; 5. x,-1+y,z; 6. x,y,1+z

\begin{tabular}{|c|c|c|c|}
\hline \multicolumn{4}{|c|}{ Complex 2} \\
\hline D-H $\cdots \mathbf{A}$ & $\mathbf{d}(\mathbf{H} \cdots \mathbf{A})(\AA)$ & $\mathbf{d}(\mathbf{D} \cdots \mathbf{A})(\AA)$ & $\angle \mathbf{D}-\mathbf{H} \cdots \mathbf{A}\left(^{\circ}\right)$ \\
\hline $\mathrm{O}(3)-\mathrm{H}(3 \mathrm{~A}) \cdots \mathrm{N}(8)^{1}$ & $2.14(5)$ & $2.912(4)$ & $170(5)$ \\
\hline $\mathrm{O}(3)-\mathrm{H}(3 \mathrm{~B}) \cdots \mathrm{N}(1)^{2}$ & 2.2762 & $2.861(3)$ & 128.64 \\
\hline $\mathrm{N}(3)-\mathrm{H}(3 \mathrm{C}) \cdots \mathrm{O}(4)^{2}$ & $2.07(4)$ & $2.842(4)$ & $168(4)$ \\
\hline $\mathrm{O}(4)-\mathrm{H}(4 \mathrm{~A}) \cdots \mathrm{O}(3)^{2}$ & $2.08(5)$ & $2.792(4)$ & $174(4)$ \\
\hline $\mathrm{O}(4)-\mathrm{H}(4 \mathrm{~B}) \cdots \mathrm{O}(6)^{2}$ & $1.93(6)$ & $2.731(4)$ & $162(7)$ \\
\hline $\mathrm{O}(5)-\mathrm{H}(5 \mathrm{~A}) \cdots \mathrm{N}(4)^{2}$ & $2.05(7)$ & $2.800(5)$ & $164(7)$ \\
\hline $\mathrm{O}(5)-\mathrm{H}(5 \mathrm{~B}) \cdots \mathrm{I}(1)^{2}$ & $2.89(4)$ & $3.576(4)$ & $166(4)$ \\
\hline $\mathrm{O}(6)-\mathrm{H}(6 \mathrm{~A}) \cdots \mathrm{O}(5)^{3}$ & $1.92(5)$ & $2.690(5)$ & $167(6)$ \\
\hline $\mathrm{O}(6)-\mathrm{H}(6 \mathrm{~B}) \cdots \mathrm{I}(1)^{4}$ & $2.81(5)$ & $3.571(3)$ & $180(5)$ \\
\hline $\mathrm{N}(7)-\mathrm{H}(7 \mathrm{C}) \cdots \mathrm{I}(1)^{3}$ & $2.88(3)$ & $3.643(3)$ & $166(4)$ \\
\hline $\mathrm{C}(2)-\mathrm{H}(2) \cdots \mathrm{I}(1)^{2}$ & 3.0188 & $3.843(4)$ & 148.53 \\
\hline $\mathrm{C}(3)-\mathrm{H}(3) \cdots \mathrm{O}(5)^{4}$ & $2.56(4)$ & $3.411(5)$ & $152(3)$ \\
\hline $\mathrm{C}(6)-\mathrm{H}(6) \cdots \mathrm{O}(6)^{2}$ & 2.555 & $3.421(4)$ & 154.93 \\
\hline $\mathrm{C}(12)-\mathrm{H}(12) \cdots \mathrm{O}(4)^{2}$ & 2.4725 & $3.167(3)$ & 131.51 \\
\hline $\mathrm{C}(13)-\mathrm{H}(13) \cdots \mathrm{O}(1)^{5}$ & 2.5203 & $3.196(4)$ & 129.85 \\
\hline Symmetry code: $1.1+$ & 2. $\mathrm{x}, \mathrm{y}, \mathrm{z} ; 3 .-1+\mathrm{z}$ & 4. 1-x,1-y,-z; 5 . & \\
\hline D-H $\cdots A$ & $\mathbf{d}(\mathbf{H} \cdots \mathbf{A})(\AA)$ & $\begin{array}{r}\text { Complex } 3 \\
\mathbf{d}(\mathbf{D} \cdots \mathbf{A})(\AA)\end{array}$ & $\angle \mathbf{D}-\mathbf{H} \cdots \mathbf{A}\left({ }^{\circ}\right)$ \\
\hline $\mathrm{N}(2)-\mathrm{H}(3 \mathrm{C}) \cdots \mathrm{O}(5)^{1}$ & 2.1646 & $2.996(3)$ & 162.27 \\
\hline $\mathrm{O}(3)-\mathrm{H}(3 \mathrm{D}) \cdots \mathrm{O}(9)^{2}$ & $2.33(2)$ & $3.231(6)$ & $164(2)$ \\
\hline $\mathrm{O}(3)-\mathrm{H}(3 \mathrm{E}) \cdots \mathrm{N}(5)^{3}$ & $1.93(2)$ & $2.855(4)$ & $168.4(19)$ \\
\hline $\mathrm{O}(4)-\mathrm{H}(4 \mathrm{D}) \cdots \mathrm{O}(9)^{2}$ & $2.26(2)$ & $3.032(5)$ & $146(3)$ \\
\hline $\mathrm{O}(4)-\mathrm{H}(4 \mathrm{E}) \cdots \mathrm{N}(1)^{4}$ & $1.93(2)$ & $2.809(4)$ & $166(2)$ \\
\hline $\mathrm{N}(6)-\mathrm{H}(6 \mathrm{C}) \cdots \mathrm{O}(10)^{5}$ & 2.1759 & $2.916(6)$ & 144.04 \\
\hline $\mathrm{C}(4)-\mathrm{H}(4) \cdots \mathrm{O}(5)^{1}$ & 2.3913 & $3.264(4)$ & 156.46 \\
\hline
\end{tabular}

Symmetry code: 1 . -x,1-y,1-z; 2. -1+x,1+y,z; 3. 1-x,2-y,-z; 4. -1-x,1-y,1-z; 5. x, y, z 
dimeric compound $\mathbf{1}$ with atom numbering scheme is depicted in figure 2a. Asymmetric unit of $\mathbf{1}$ is composed of one $\mathrm{K}^{+}$centre, one $\mathrm{Br}^{-}$anion, two molecules of $\mathbf{L}$, one coordinated water molecule and three water molecules as solvent of crystallization.

Each symmetrically disposed $\mathrm{K}^{+}$in the dimeric unit is wrapped around by two $\mathbf{L}$ moieties. One of the $\mathbf{L}$ act as a tridentate ligand via $\mathrm{N}_{2} \mathrm{O}$ coordination with $\mathrm{K}^{+}$through its imine and pyridyl nitrogens (N6, N5) and the amide oxygen $(\mathrm{O} 2)$, while from the second $\mathbf{L}$ moiety the amide oxygen (O1) is making a $\mu_{2-}$ type coordination with the symmetrically disposed $\mathrm{K}^{+}$generating the centrosymmetric dimeric compound. Each $\mathrm{K}^{+}$is involved in an octa coordination provided by the imine/pyridyl nitrogen and amide oxygen atoms from two different $\mathbf{L}$ moieties in which amide oxygen $\mathrm{O} 1$ from one of the $\mathbf{L}$ is making $\mu_{2-}$ type coordination to bridge the adjacent $\mathrm{K}^{+}$along with one coordinated water molecule. $\mathrm{K}-\mathrm{O}$ distances in ranges from 2.787(3) to $2.945(2) / 2.815(3)$ to $3.026(2) \AA$ and K-N distance is in the range 2.843(3) to 3.275(3)/2.856(2) to 3.302(2) $\AA$ A respectively for $\mathbf{1}$ and $\mathbf{2}$ (Table $\mathrm{S} 1$ ).

Diverse supramolecular interactions are anticipated due to the presence of amide group in the ligand moiety and lattice/coordinated water molecules in 1 \& 2 . Packing diagram viewed down $a$-axis with hydrogen bonding interactions are depicted in figures $2 \mathrm{~b}$ and $\mathrm{S} 1$. Symmetrically disposed water molecule $\mathrm{O} 4$ positioned between the dimers are involved in bridging the adjacent dimeric unit to from a hydrogen bonded layers along $b$-axis. Thus, symmetrically placed water $(\mathrm{O} 4)$ acts as a donor through $\mathrm{O}-\mathrm{H} \cdots \mathrm{O}$ contact with the coordinated water $\mathrm{O} 3$ and an acceptor via $\mathrm{N}-\mathrm{H}$... O contacts with the amide hydrogen $\mathrm{H} 7 \mathrm{~N}$ in the formation

a
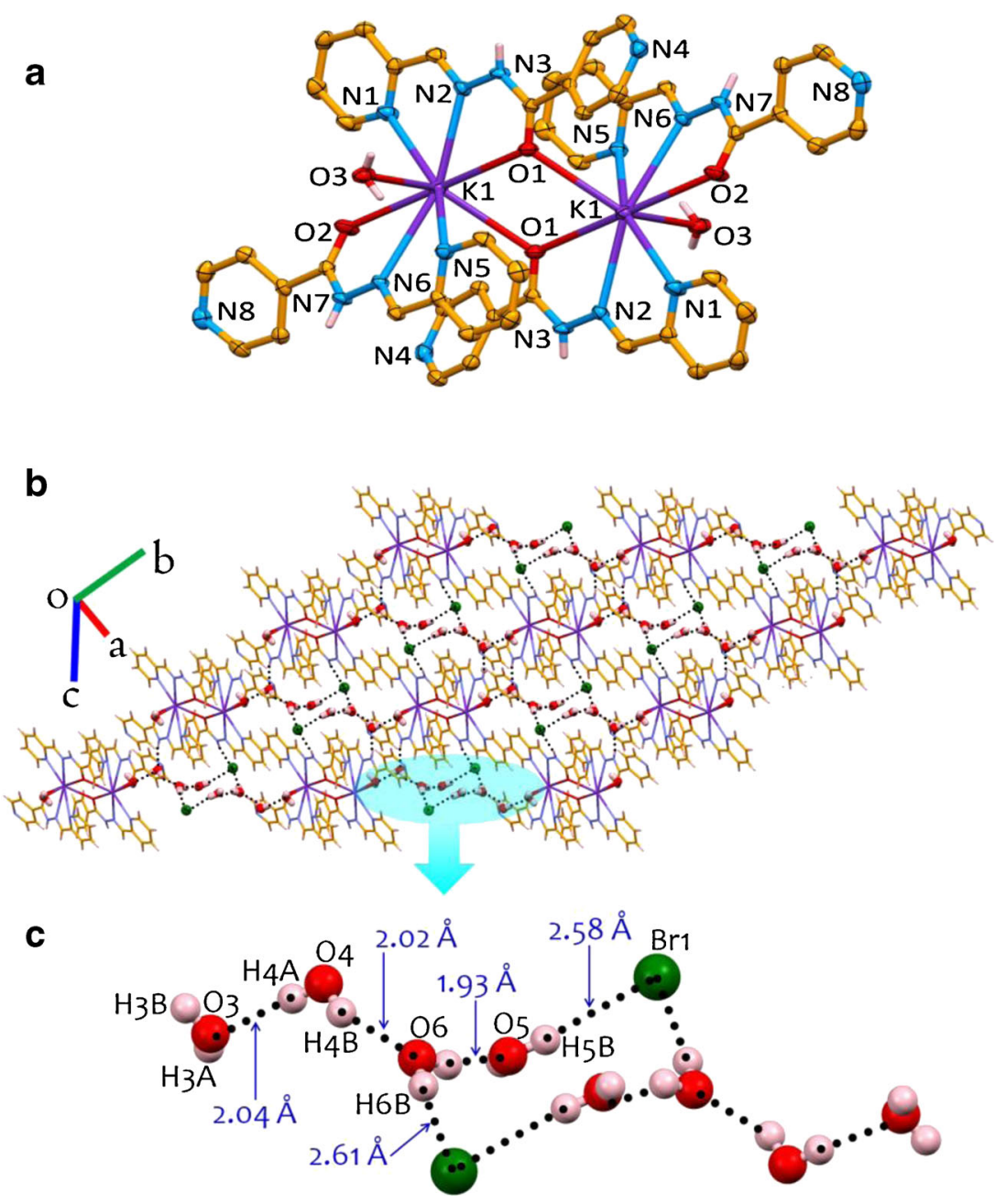

Figure 2. (a) ORTEP diagram of $\mathbf{1}$ depicting 50\% probability for thermal ellipsoids with atom numbering scheme (Some of the hydrogen atoms, bromide anions and lattice water molecules have been omitted for clarity); (b) packing diagram presenting the hydrogen bonded $2 \mathrm{D}$ sheets spreading along bc-plane; (c) centrosymmetric hexameric $\left[\left(\mathrm{H}_{2} \mathrm{O}\right)_{4}\left(\mathrm{Br}^{-}\right)_{2}\right]$ cluster observed in $\mathbf{1}$. 
of the hydrogen bonded layers along $b$-axis. Extensive hydrogen bonding interactions do exist in 1 \& 2 between the lattice water molecules O5 and O6 with the bromide/iodide anions in generating a hybrid water-bromide puckered ring with chair conformation as depicted in figure 2c. Lattice Water molecules $\mathrm{O} 5$ and $\mathrm{O} 6$ are mutually involved in $\mathrm{O}-\mathrm{H}$... O hydrogen bonding in which $\mathrm{O} 6$ acts as a donor and $\mathrm{O} 5$ as acceptor. Thus, H6A attached to $\mathrm{O} 6$ render as the donor and involved in $\mathrm{O}-\mathrm{H} \cdots \mathrm{O}$ interactions with $\mathrm{O} 5$ and $\mathrm{H} 6 \mathrm{~B}$ and $\mathrm{H} 5 \mathrm{~B}$ from $\mathrm{O} 6$ and $\mathrm{O} 5$ respectively are drawn into $\mathrm{O}-\mathrm{H} \cdot \cdots \mathrm{Br}^{-}$contacts generating a cyclic centrosymmetric hexameric $\left[\left(\mathrm{H}_{2} \mathrm{O}\right)_{4}\left(\mathrm{Br}^{-}\right)_{2}\right]$ cluster (figure 2c). The $\mathrm{O} \cdots \mathrm{O}$ distances, $\mathrm{O}-\mathrm{H} \cdots \mathrm{O}$ and angles within this basic centrosymmetric $\left[\left(\mathrm{H}_{2} \mathrm{O}\right)_{4}\left(\mathrm{Br}^{-}\right)_{2}\right]$ unit generating a eleven membered cyclic ring are $\mathrm{O}(5) \cdots \mathrm{O}(6)$ $=2.707(6) \AA$, with $\angle \mathrm{O}(6)-\mathrm{H}(6 \mathrm{~A}) \cdots \mathrm{O}(5)=163(5)^{\circ}$ and; the $\mathrm{O} \cdots \mathrm{Br} 1$ distances and $\mathrm{O}-\mathrm{H} \cdots \mathrm{Br}^{-}$angles are $(\mathrm{Br} 1 \cdots \mathrm{O} 5=3.363(4) \AA, \mathrm{Br} 1 \cdots \mathrm{O} 6=3.372(4) \AA$ and $\angle \mathrm{O} 5-\mathrm{H} 5 \mathrm{~B} \cdots \mathrm{Br} 1=165(5)^{\circ}, \angle \mathrm{O} 6-\mathrm{H} 6 \mathrm{~B} \cdots \mathrm{Br} 1=$ $\left.174(5)^{\circ}\right)$ respectively. Centrosymmetric six membered $\left[\left(\mathrm{H}_{2} \mathrm{O}\right)_{4}\left(\mathrm{Br}^{-}\right)_{2}\right]$ rings are placed between the hydrogen bonded 1D layers and involved in $\mathrm{O}-\mathrm{H} \cdots \mathrm{O}, \mathrm{N}$ $\mathrm{H} \cdots \mathrm{O}$ and $\mathrm{N}-\mathrm{H} \cdots \mathrm{Br}$ contacts along $c$-axis generating a two dimensional hydrogen bonded network (figure $2 \mathrm{~b}$ ). In addition to the above mentioned hydrogen bonds inter and intra molecular $\mathrm{C}-\mathrm{H}$... O as well as C$\mathrm{H} \cdots \mathrm{Br}^{-}$contacts are also observed in supramolecular assembly resulting in the stabilisation of molecules in crystal lattice. Similar molecular interactions are persistent in the isostructural compound $\mathbf{2}$ with counter anion $\mathrm{I}^{-}$(figure S1). Details of all the hydrogen bonding interactions present in $\mathbf{1}$ and $\mathbf{2}$ with symmetry codes are given in table 2 .

\subsection{Crystal and molecular structure of $\left[\mathrm{Ba}(\mathrm{L})_{2}\left(\mathrm{H}_{2} \mathrm{O}\right)_{2}\left(\mathrm{ClO}_{4}\right)\right] \mathrm{ClO}_{4}(3)$}

Complex 3 crystallized in triclinic system with P-1 space group. ORTEP diagram for mono-cationic complex part of $\mathbf{3}$ is depicted in figure 3. Nona coordination adopted by $\mathrm{Ba}^{+2}$ is provided by two $\mathbf{L}$ moieties in chelated tridentate fashion through its pyridyl, imine nitrogen atoms (N4, N8 and N3, N7), amide oxygen atoms $(\mathrm{O} 1$ and $\mathrm{O} 2)$, two water molecules $(\mathrm{O} 3$ and $\mathrm{O} 4)$ and one perchlorate oxygen $(\mathrm{O} 5)$. Ba-O distances involving the amide oxygen and water molecules ranges from 2.714(2) to 2.956(3) $\AA$ and Ba-N distances involving the pyridyl/amide nitrogen is in the range of 2.893(2) to 2.965(2) A respectively.

In an attempt to understand the supramolecular interaction in $\mathbf{3}$ we have analysed the packing and

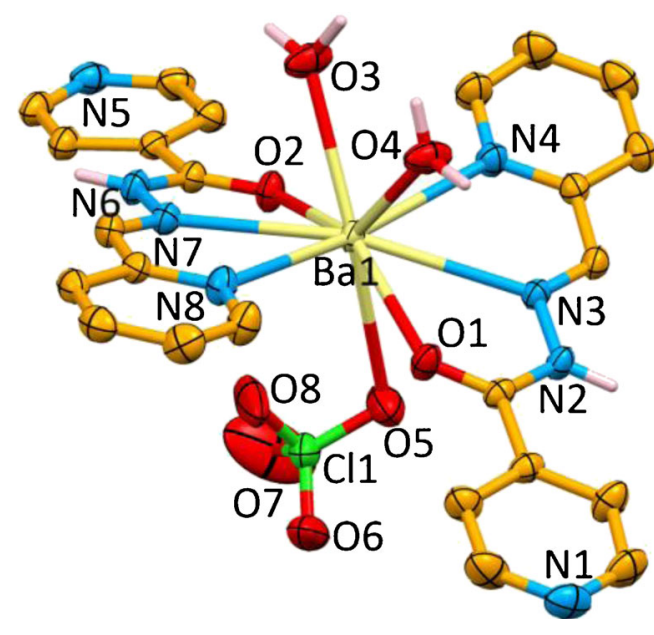

Figure 3. ORTEP diagram depicting of the monocationic part of 3 with atom numbering scheme (50\% probability for thermal ellipsoids; only amide hydrogen atoms and one of the disordered position for the coordinated perchlorate moiety is shown).

hydrogen bonding interaction in detail. Packing diagram with hydrogen bonding interaction viewed down $b$-axis is depicted in figure $4 \mathrm{a}$ and shows that the monomeric cations are oriented along $c$-axis. Detailed analysis of observed hydrogen bonding interaction (figure $4 \mathrm{~b}$ ) expose that the 2D supramolecular sheet is stabilized by several weak molecular contacts. $\mathrm{N}$ $\mathrm{H} \cdots \mathrm{O}, \mathrm{O}-\mathrm{H} \cdots \mathrm{O}$ and $\mathrm{C}-\mathrm{H} \cdots \mathrm{O}$ interactions involving the coordinated/lattice perchlorate anion with complex moiety play a crucial role for the association of the discrete complex entities generating a layered motif along $c$-axis. Thus, amide hydrogen atoms H6C and $\mathrm{H} 3 \mathrm{C}$ from N6/N2, water hydrogen $\mathrm{H} 3 \mathrm{D}$ and $\mathrm{H} 4 \mathrm{D}$ from $\mathrm{O} 3 / \mathrm{O} 4$ and pyridyl hydrogen $\mathrm{H} 4 \mathrm{C}$ from $\mathrm{C} 4$ is involved in intermolecular contacts with perchlorate oxygen atoms as cited [N6-H6C $\cdots$ O 10: H6C $\cdots \mathrm{O} 10=(2.18$ $\AA), \mathrm{N}(2)-\mathrm{H} 3 \mathrm{C} \cdots \mathrm{O}(5): \mathrm{H} 3 \mathrm{C} \cdots \mathrm{O}(5)=(2.16 \AA), \mathrm{O} 3-$ H3D... O9: H3D ...O9 = (2.33(2) A, O4-H4D ...O9:

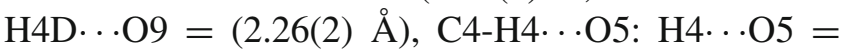
$(2.39 \AA)$ ]. Intermolecular $\mathrm{O}-\mathrm{H} \cdots \mathrm{N}$ interactions involving coordinated water hydrogen (H4E and H3E) and terminal pyridine nitrogen of ligand $\mathbf{L}[(\mathrm{O} 4-\mathrm{H} 4 \mathrm{E} \cdots \mathrm{N} 1$ : $\mathrm{H} 4 \mathrm{E} \cdots \mathrm{N} 1=1.93(2) \AA$ and O3-H3E $\cdots \mathrm{N} 5: \mathrm{H} 3 \mathrm{E} \cdots \mathrm{N} 5$ $=1.93(2) \AA]$ from neighbouring units of layered hydrogen bonded motif extending the supramolecular array along $a$-axis generating a two dimensional hydrogen bonded network in $\mathbf{3}$. In addition to the above mentioned hydrogen bonding interactions the pyridyl rings ( $\mathrm{N}(5)-\mathrm{C}(13)$ to $\mathrm{C}(17))$ of the ligand moieties are involved in intermolecular $\pi \cdots \pi$ stacking interactions along $a$-axis with centroid $\cdots$ centroid distance between the pyridyl rings $3.68 \AA$ [symmetry code $1-x, 2-y,-z]$. 


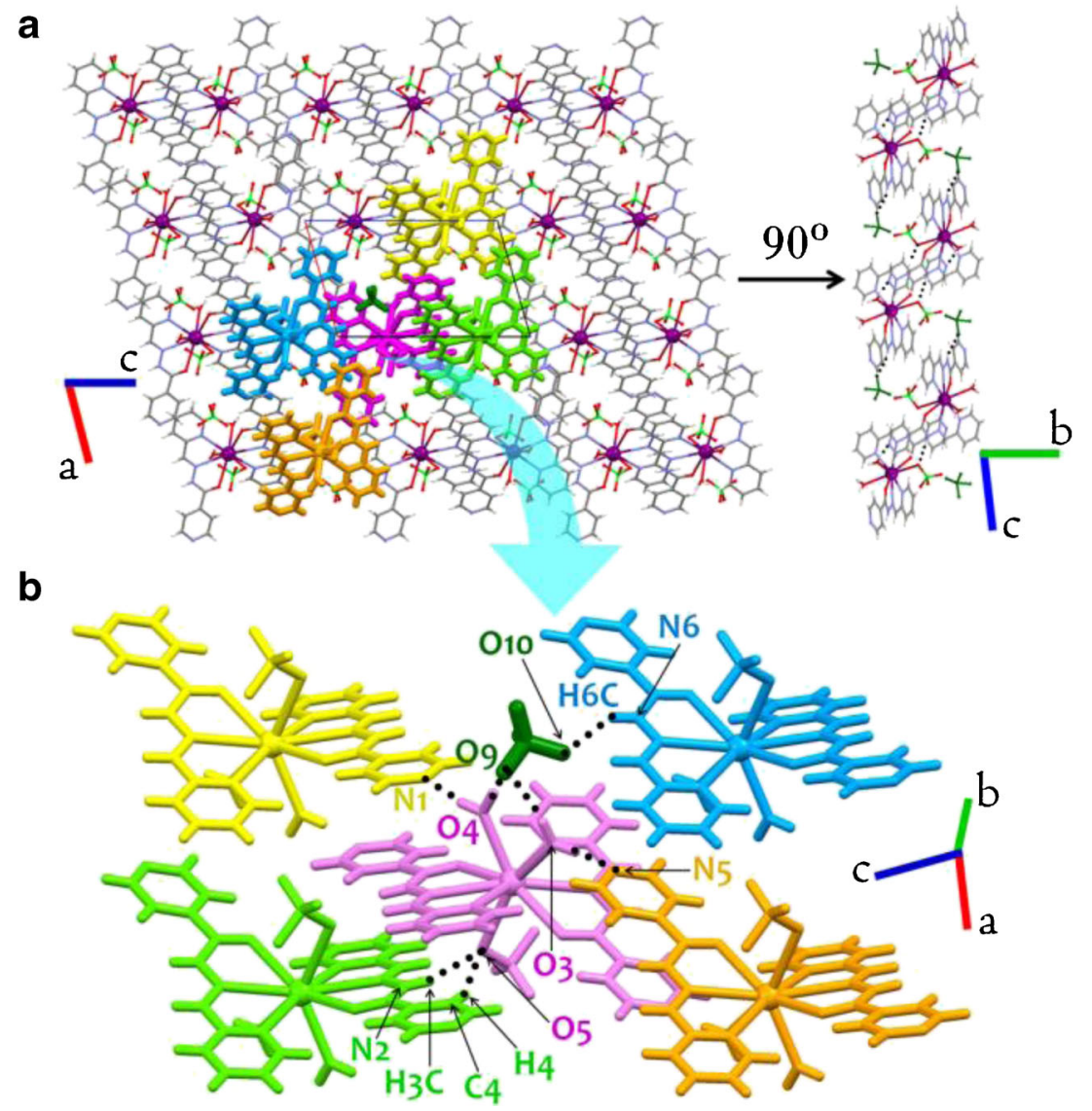

Figure 4. (a) Packing diagram viewed down b- and a- axes for 3; (b) close-up view of the various H-bonding (Black dotted lines) present in $\mathbf{3}$.

\subsection{TGA and PXRD analyses}

The lattice guests and composition of $\mathbf{L}$ and $\mathbf{1 - 3}$ were estimated and ascertained by thermal, elemental and single crystal analyses. Lattice water molecules in case of $\mathbf{L} . \mathbf{2} \mathrm{H}_{2} \mathrm{O}\left(\mathrm{C}_{12} \mathrm{H}_{10} \mathrm{~N}_{2} \mathrm{O}\right.$. $\left.\left(\mathrm{H}_{2} \mathrm{O}\right)_{2}\right)$ escape from the crystal lattice in the temperature range $40-128^{\circ} \mathrm{C}$, evident from the thermogram showing $\mathrm{ca} 9 \%$ weight loss (calc. 13.73\%) in the mentioned temperature range (figure 5). Dehydrated ligand $\mathbf{L}$ thus obtained exhibits thermal stability up to $200^{\circ} \mathrm{C}$ and further increment in temperature resulted in the decomposition of ligand. Complex 1, $\left(\left[\mathrm{K}_{2} \mathbf{L}_{4}\left(\mathrm{H}_{2} \mathrm{O}\right)_{2}\right] \mathrm{Br}_{2} \cdot 6 \mathrm{H}_{2} \mathrm{O}\right)$ lose lattice water molecules at ambient conditions; however, expulsion of coordinated water molecules (obs. ca $3 \%$; calc. $2.8 \%$ ) in temperature range $70-165^{\circ} \mathrm{C}$ was observed. Compound 1 decomposes at temperature higher than $200^{\circ} \mathrm{C}$. Lattice (calc. $7.82 \%$ ) and coordinated (calc. $2.60 \%$ ) water molecules in case of complex 2, $\left(\left[\mathrm{K}_{2} \mathrm{~L}_{4}\left(\mathrm{H}_{2} \mathrm{O}\right)_{2}\right] \mathrm{I}_{2} \cdot 6 \mathrm{H}_{2} \mathrm{O}\right)$ escape stepwise manner in the temperature range $30-165^{\circ} \mathrm{C}$ for which $9.2 \%$ weight loss was observed. Complex $\mathbf{3}$, $\left[\mathrm{BaL}_{2}\left(\mathrm{H}_{2} \mathrm{O}\right)_{2}\left(\mathrm{ClO}_{4}\right)\right] .\left(\mathrm{ClO}_{4}\right)$ exhibit $3.10 \%$ weight loss when heated up to $150^{\circ} \mathrm{C}$ which is attributable to the two coordinated water molecules (calc. $4.36 \%$ ). Complex 3, exhibits thermal stability up $285^{\circ} \mathrm{C}$ and further increase in temperature cause rapid decomposition of compound. Experimental PXRD data obtained for bulk samples of $\mathbf{L} .2 \mathrm{H}_{2} \mathrm{O}$ as well as complexes corroborate well with those simulated from respective single crystal data (figures S2 and S3) confirming the phase purity of synthesized samples.

\subsection{FTIR and absorption spectra}

FTIR spectra for both pseudopolymorphs and all three complexes were recorded at room temperature by dispersing minute amount of solids in $\mathrm{KBr}$ pellets (figure 6). FTIR spectra of ligand pseudopolymorphs featured comparable bands for carbonyl and imine stretching modes at 1665 and $1549 \mathrm{~cm}^{-1}$ for $\mathbf{L}$ and at 1665 and $1567 \mathrm{~cm}^{-1}$ for $\mathbf{L} .2 \mathrm{H}_{2} \mathrm{O}$. Presence of water molecules in psuedopolymorph $\mathbf{L} .2 \mathrm{H}_{2} \mathrm{O}$ was revealed by broad band for $\mathrm{OH}$ stretching mode observed in $3200-3550 \mathrm{~cm}^{-1}$ range. Carbonyl and imine stretching bands in case of complexes 1-3 were observed at ca 1665 and $1550 \mathrm{~cm}^{-1}$ whereas all three complexes 

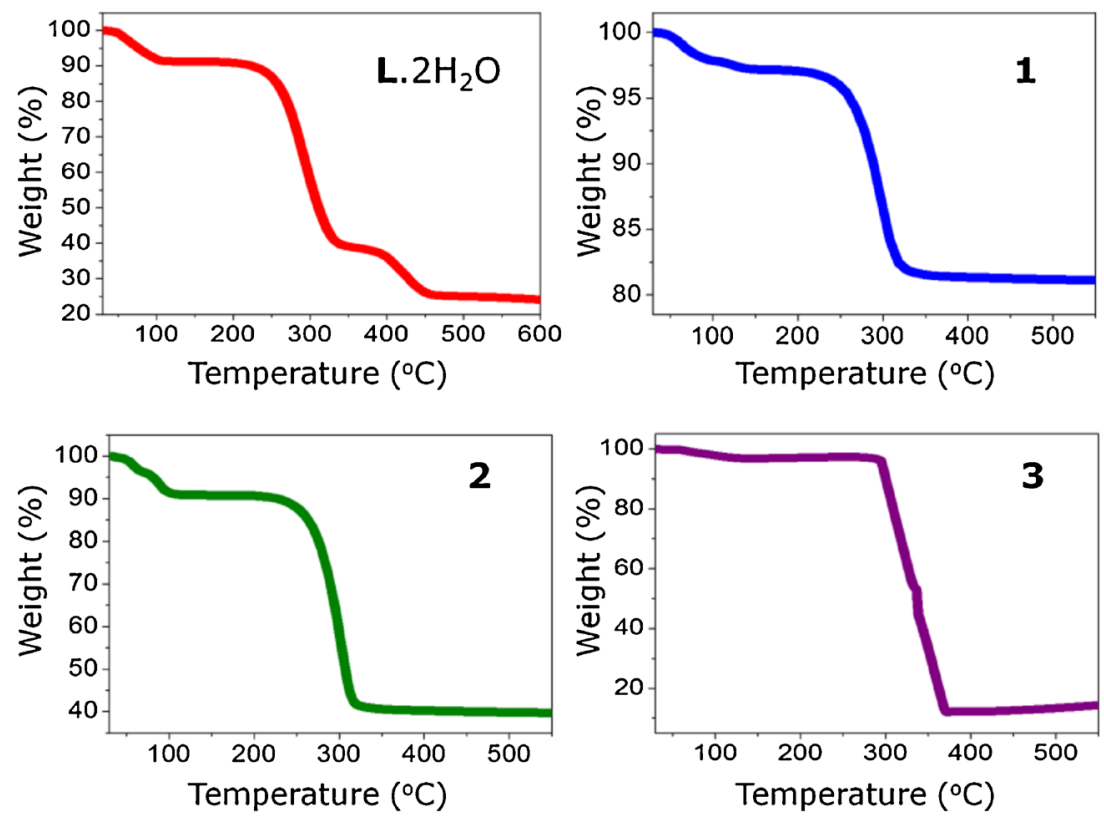

Figure 5. TGA traces for ligand pseudopolymorph $\mathbf{L} \cdot 2 \mathrm{H}_{2} \mathrm{O}$ and complexes 1-3.
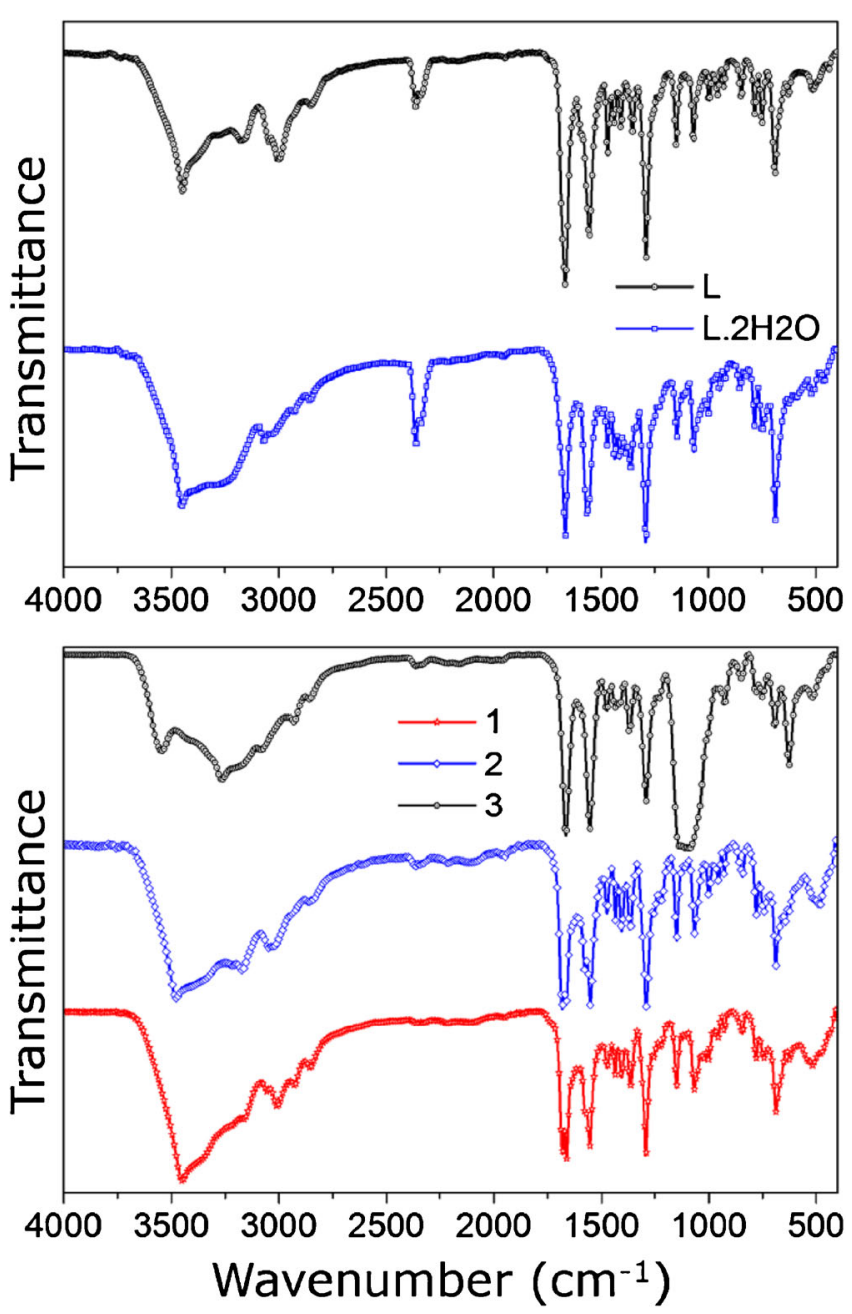

Figure 6. FTIR spectra recorded by $\mathrm{KBr}$ pellet method for L. $2 \mathrm{H}_{2} \mathrm{O}$ and complexes 1-3. exhibit broad $\mathrm{OH}$ stretching bands for coordinated and/or lattice water molecules at $c a 3475 \mathrm{~cm}^{-1}$. Cl-O stretching band was distinctly observed at $c a 1100 \mathrm{~cm}^{-1}$ in case of complex 3 .

Absorption behaviour of both psuedopolymorphic forms ( $\mathbf{L}$ and $\mathbf{L} .2 \mathrm{H}_{2} \mathrm{O}$ ) of ligand and synthesized complexes 1-3 was studied in solid state at room temperature (figure 7). $\mathbf{L}$ revealed two overlapping bands at $c a 326$ and $261 \mathrm{~nm}$ which can be ascribed as $\pi$ $\pi^{*}$ and $\pi-n$ transitions. However, these bands were much diffused in case of $\mathbf{L} \cdot 2 \mathrm{H}_{2} \mathrm{O}$ and appeared as a broad band spanning in 360-233 $\mathrm{nm}$ range. Complexes 1-3 showed similar absorption spectral feature as of

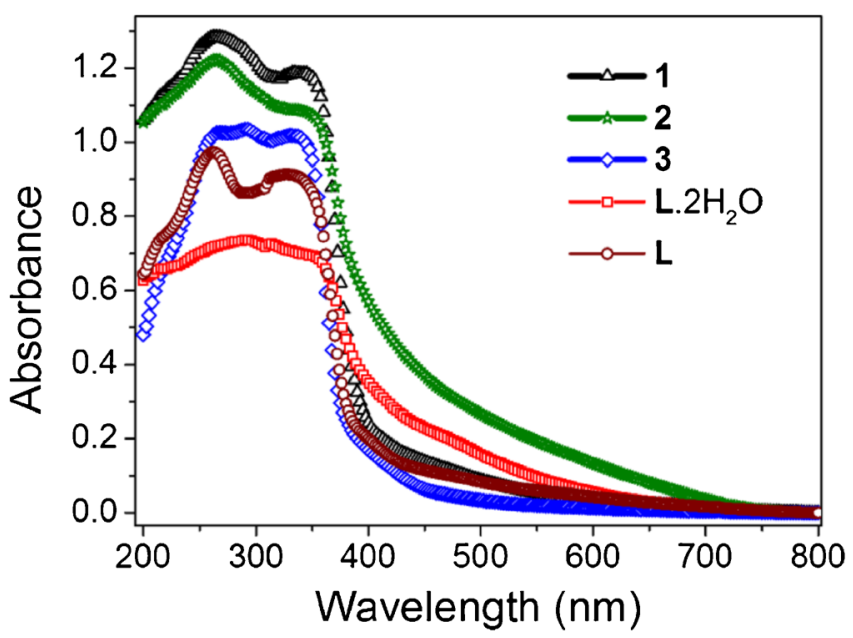

Figure 7. Solid state absorption spectra for pseudopolymorphs $\mathbf{L}, \mathbf{L} .2 \mathrm{H}_{2} \mathrm{O}$ and complexes 1-3. 
constituting ligand, suggesting the persistent intraligand or metal perturbed intraligand electronic transitions.

\section{Conclusions}

We have reported a new psuedopolymorph of a O,N,N'donor hydrazone ligand, 2-pyridylcarboxaldehyde isonicotinoylhydrazone $(\mathbf{L})$ and its discrete complexes with $\mathrm{K}^{+}$and $\mathrm{Ba}^{2+}$ which present as first examples of complexes between $\mathbf{L}$ and alkali or alkaline earth metal ions. All compounds were characterized by single crystal X-ray structural analysis and other physicochemical techniques such as FTIR, TGA, PXRD and solid state absorption spectra. $\mathbf{L}$ formed isostructural dinuclear complexes with $\mathrm{K}^{+}$when bromide and iodide were employed as counteranion, whereas, a mononuclear complex with $\mathrm{Ba}^{2+}$ was formed which showed coordinated as well as uncoordinated perchlorate counter anion. Various structural aspects including hydrogen bonding interactions and spectral features of $\mathbf{L} .2 \mathrm{H}_{2} \mathrm{O}$ and 1-3 have been studied in detail.

\section{Supplementary Information}

Crystallographic data of for the psuedopolymorhic form of $\mathrm{L} .2 \mathrm{H}_{2} \mathrm{O}$, complexes $\mathbf{1}, \mathbf{2}$ and $\mathbf{3}$ has been deposited at the Cambridge Crystallographic Data Centre with CCDC nos. 992911 to 991914 respectively. Copies of this information can be obtained free of charge from The Director, CCDC, 12 Union Road, Cambridge, CB2 IEZ, UK (Fax: +44-1223-336033; Email: deposit@ccdc.cam.ac.uk or http://www.ccdc. cam.ac.uk). Characterization data for the ligand and complexes such experimental and simulated PXRD for L. $2 \mathrm{H}_{2} \mathrm{O}$ (figure S2), Experimental and simulated PXRD for 1-3 (figure S2), ${ }^{1} \mathrm{H}$ and ${ }^{13} \mathrm{C}$ NMR Spectra of ligands and complexes (figure S4) and ORTEP diagram and crystal structure for complex 2 (figure S1) and selected bond lengths and angles (table S1) are available in the supporting information (www.ias.ac.in/chemsci).

\section{Acknowledgement}

Authors acknowledge the CSIR, India (K-TEN Project, Grant no. CSC 0105) for financial support, Mrs. Monika Gupta for TGA data, Ms. Riddhi Laiya for XRPD data, Mr. Satyaveer Gothwal for elemental data, Mr. Viral Vakani for IR data. BP and KKB acknowledge CSIR (India) for research fellowships. Publication Registration Number: CSIR-CSMCRI No. : 066/2014.

\section{References}

1. (a) Desiraju G R 2007 Angew. Chem. Int. Ed. 46 8342; (b) Vantomme G and Lehn J M 2013 Angew. Chem. Int. Ed. 523940

2. (a) Fahmi N, Shrivastava S, Meena R, Joshi S C and Singh R V 2013 New J. Chem. 37 1445; (b) Armstrong C M, Bernhardt P V, Chin P and Richardson D R 2003 Eur. J. Inorg. Chem. 1145; (c) Singh N, Watts S, Joshi S C and Singh R V 2013 Appl. Organometal. Chem. 27 269; (d) Ababei L V, Kriza A, Andronescu C and Musuc A M 2012 J. Therm. Anal. Calorim. 107 573; (e) Shahverdizadeh G H, Tiekink E R T and Mirtamizdoust B 2011 Acta Crystallogr., Sect. E: Struct. Rep. Online $67 \mathrm{~m} 1727$

3. (a) Bernhardt P V, China P and Richardson D R 2004 Dalton Trans. 3342; (b) Sharma V K, Srivastava S and Srivastava A 2006 J. Coord. Chem. 59 1321; (c) Sastry P S S J and Rao T R 1995 Proc. Indian Acad. Sci. (Chem. Sci.) 107 25; (d) Bikas R, Hosseini-Monfared H, Zoppellaro G, Herchel R, Tucek J, Owczarzak A M, Kubicki M and Zboril R 2013 Dalton Trans. 422803

4. Richardson D R, Becker E and Bernhardt P V 1999 Acta Crystallogr., Sect. C: Cryst. Struct. Commun. 552102

5. Bernhardt P V, Chin P and Richardson D R 2001 J. Biol. Inorg. Chem. 6801

6. (a) Bernhardt P V, Caldwell L M, Chaston T B, Chin P and Richardson D R 2003 J. Biol. Inorg. Chem. 8 866; (b) Bernhardt P V, Chin P, Sharpe P C and Richardson D R 2007 Dalton Trans. 3232; (c) Bernhardt P V, Mattsson J and Richardson D R 2006 Inorg. Chem. 45 752; (d) Kalinowski D S, Sharpe P C, Bernhardt P V and Richardson D R 2008 J. Med. Chem. 51331

7. (a) Shin H and Min B 2013 J. Inorg. Organomet. Polym. 23 1305; (b) Li D Q, Liu X and Zhou J 2008 Inorg. Chem. Commun. 11 367; (c) Xua C, Maoa H, Shena $X$, Zhanga $H$, Liua $H$, Wua Q, Houa $H$ and Zhua Y 2007 J. Coord. Chem. 60 193; (d) Shaabani B, Khandar A A, Kazemi S S, Shaghaghi Z, Boudalis A K, Psycharis V and Raptopoulou A 2013 Polyhedron 4961 ; (e) Hanifehpour Y, Saraei N, Asl S M and Joo S W 2012 J. Inorg. Organomet. Polym. 22 1271; (f) Ni W X, Li M, Zhan S Z, Hou J Z and Li D 2009 Inorg. Chem. 48 1433; (g) Yu Q, Zhu L G, Bian H G, Deng G H, Bao X G and Liang H 2007 Inorg. Chem. Commun. 10 437; (h) He Z, He C, Gao E Q, Wang Z M, Yang X F, Liao C S and Yan C H 2003 Inorg. Chem. 42 2206; (i) Li D Q, Liu X and Zhou J 2010 Z. Naturforsch. B: Chem. Sci. 65 1084; (j) Li G, Yan W B, He C, Duan C Y, Meng Q J and Li Y Z 2008 Chin. J. Inorg. Chem. 24 1767; (k) Li D Q, Liu X and Zhou J 2008 Z. Naturforsch. B: Chem. Sci. 63 1343; (1) Cai T J, Long Y F, Deng Q and Peng Z S 2005 Z. Kristallogr. New Cryst. Struct. 220 506; (m) Cai T J, Peng Z S, Deng Q, Long Y F, Deng T T and Yu K B 2004 Chin. J. Inorg. Chem. 20 731; (n) Hanifehpour Y, Khanalilou S, Paknahad E, Joo S W, Sadr M H and Soltani B 2012 J. Inorg. Organomet. Polym. Mater. 221248

8. Heine J, Hołyńska M, Reuter M, Haas B, Chatterjee S, Koch M, Gries K I, Volz K and Dehnen S 2013 Cryst. Growth Des. 131252

9. (a) Rodríguez-Spong B, Price C P, Jayasankar A, Matzger A J and Rodríguez-Hornedo N. 2004 Adv. Drug Deliv. Rev. 56 241; (b) Mukherjee A, Tothadi S, 
Chakraborty S, Ganguly S and Desiraju G R 2013 CrystEngComm 15 4640; (c) Bhargavi G, Rajasekharan M V, Costes J P and Tuchagues J P 2013 Dalton Trans. 42 8113; (d) Grobelny P, Mukherjee A and Desiraju G R 2012 CrystEngComm 14 5785; (d) Aravinda S, Shamala N, Karle I L and Balaram P 2012 Pept. Sci. 98 76; (e) Aitipamula S, Banerjee R, Bansal A K, Biradha K, Cheney M L, Choudhury A R, Desiraju G R, Dikundwar A G, Dubey R, Duggirala N, Ghogale P P, Ghosh S, Goswami P K, Goud N R, Jetti R K R, Karpinski P, Kaushik P, Kumar D, Kumar V, Moulton B, Mukherjee A, Mukherjee G, Myerson A S, Puri V, Ramanan A, Rajamannar T, Reddy C M, Rodriguez-Hornedo N, Rogers R D, Row T N G, Sanphui P, Shan N, Shete G, Singh A, Sun C C, Swift J A, Thaimattam R, Thakur T S, Thaper R K, Thomas S P, Tothadi S, Vangala V R, Vishweshwar P, Weyna D R and Zaworotko M J 2012 Cryst. Growth Des. 12 4290; (f) Mukherjee A, Grobelny P, Thakur T S and Desiraju G R 2011 Cryst. Growth Des. 11 2637; (g) Chieng N, Rades T and Aaltonen J 2011 J. Pharm. Biomed. Anal. 55 618; (h) Thakur T S, Sathishkumar R, Dikundwar A G, Row T N G and Desiraju G R 2010 Cryst. Growth Des. 10 4246; (i) Nangia A and Desiraju G R 1999 Chem. Commun. 605

10. (a) Patidar R, Paul P and Ganguly B 2013 J. Mol. Graph. Model. 46 22; (b) Maiti P, Ghosh P K, Ghara K K,
Solanki J, Brahmbhatt H R, Chunawala J R, Suresh E and Paul P 2013 PCT Int. Appl. WO 2013150363 A1 20131010; (c) Ramakrishna V, Patra S, Suresh E, Bhatt A K, Bhatt P A, Hussain A and Paul P 2012 Inorg. Chem. Commun. 22 85; (d) Patra S, Suresh E and Paul P 2007 Polyhedron 26 4971; (e) Bisht K K, Rachuri Y, Parmar B and Suresh E 2014 J. Solid State Chem. 213 43; (f) Kathalikkattil A C, Damodaran S, Bisht K K and Suresh E 2011 J. Mol. Struct. 985 361; (g) Kathalikkattil A C, Bisht K K, Subramanian P S and Suresh E 2010 Polyhedron 29 1801; (h) Bisht K K, Patel P, Rachuri Y and Suresh E 2014 Acta Crystallogr. Sect. B-Struct. Sci. 70 63; (i) Bisht K K, Rachuri, Y, Parmar B and Suresh E 2014 RSC Adv. 47352

11. (a) Aakeröy C B, Forbes S and Desper J 2012 Cryst. Eng. Comm. 14 2435; (b) Johnson D K, Murphy T B and Rose N J 1982 Inorg. Chim. Acta 67159

12. Sheldrick G M SAINT 5.1 ed., Siemens Industrial Automation Inc., Madison, WI, 1995

13. SADABS, Empirical Absorption Correction Program, University of Göttingen, Göttingen, Germany, 1997

14. Sheldrick G M SHELXTL Reference Manual: Version 5.1, Bruker AXS, Madison, WI, 1997

15. Sheldrick G M SHELXL-97: Program for Crystal Structure Refinement, University of Göttingen, Göttingen, Germany, 1997 